\title{
Consideraciones acerca de la cualificación en la mano de obra del inmigrante trabajador en Colombia
}

Considerations about the qualification in the labor force of the immigrant worker in Colombia

Milena Paola Mena-Cuesta ${ }^{1}$

Adriana Torres de Arguelles ${ }^{2}$

Tipo de artículo: Ensayo. Recibido: 02 de octubre de 2019. Aprobado: 02 de diciembre de 2019.

Resumen: La presente investigación tiene como propósito interpretar el impacto del inmigrante trabajador en Colombia desde una perspectiva económica-laboral. Para ello, se consultaron algunos expertos en la temática. La metodología empleada consistió en un estudio bibliográfico con un enfoque cualitativo. Es imperativo señalar que el estudio se aborda desde un enfoque económicolaboral, al presumirse ser producto de efectos inducidos desde la dinámica de la geopolítica internacional. Sin embargo, aunque esta afirmación no constituye un elemento determinante de la investigación, se menciona como referente necesario para contextualizar lo que sucede en Colombia, dejando de lado, por supuesto, los intereses o sesgos políticos que circundan este problema social. Así como las consideraciones sobre el tema de la inmigración en general y los motivos de su desplazamiento, que proyectan a lo interno de Colombia una serie de desafíos que se reflejan en los ámbitos territorial y extraterritorial.

Palabras clave: Cualificación laboral, Migración, Inmigración, Emigración

\begin{abstract}
This research aims to interpret the impact of the immigrant worker in Colombia from an economiclabor point of view. For this, some expert authors on the subject were consulted. The methodology used consisted of a bibliographic study with a qualitative approach. It is necessary to point out that the study is approached from an economic-labor approach, as it is presumed to be the product of induced effects from the dynamics of international geopolitics. However, although this statement does not constitute a determining element of the investigation, it is mentioned as a necessary reference in the contextualization of what is happening in Colombia, separating, of course, the political interests or biases that surround this social problem. As well as the considerations on the subject of immigration in general and the reasons for its displacement, which project a series of challenges that reflect in the territorial and extraterritorial fields within Colombia.
\end{abstract}

1 Doctora en Ciencias Gerenciales, magíster en Talento Humano, abogada, docente investigadora de la Institución Universitaria Tecnológico de Antioquia. Correo electrónico: milemena@gmail.com

2 Postdoctora en Gerencia de la Educación Superior, doctora en Ciencias Gerenciales, magíster en Docencia para la Educación Superior, ingeniera industrial, docente e investigadora de la Universidad del Zulia (Venezuela). Correo electrónico: torrefanet@gmail.com 
Keywords: Labor qualification - Migration - Immigration - Emigration

Cómo citar este artículo: Mena-Cuesta, M. P. y Torres de Arguelles, A. (2020). Consideraciones de la cualificación en la mano de obra del inmigrante trabajador en Colombia. Memorias Forenses, (3), 74-83.

\section{Introducción}

Sobre la percepción del fenómeno de la inmigración en Colombia, al igual que en el resto de los países latinoamericanos, las migraciones poblacionales suelen significar un problema que impacta directamente en la economía, la seguridad nacional y sobre todo en el mercado laboral interno; por lo menos en un significativo número de investigaciones editadas se encuentra al respecto, que no todos los efectos son negativos (aunque se reconoce que existen), por el contrario, se maneja la tesis de considerar los "efectos marginales" como beneficiosos para la nación anfitriona, claro está, "dependiendo de las características de la población migrante, podría tener impactos positivos" (OECD e ILO, 2018 y Pekkala y Kerr, 2011, citados en Fedesarrollo, 2018, p. 5).

Al analizar la dinámica reciente de los principales indicadores de mercado laboral colombiano desde la perspectiva de Fedesarrollo (2018), los colombianos se han constituido como un país de tránsito, en algunos casos restringiendo la posibilidad de permanencia, a través de estrategias como la suspensión de la entrega del carné fronterizo y el trámite del visado de residente como requisito para la nacionalización, lo que significa un incentivo al trabajo informal para los inmigrantes sin documentos que deciden quedarse.

Quizá las decisiones políticas hayan sido determinantes, en cuanto se ha producido un incremento drástico de la tasa de ocupación informal, que evidencia la superación de la capacidad del mercado laboral de absorber la población económicamente activa y en especial a los migrantes, por ser una mano de obra (cualificada o no) con un menor costo de desembolso salarial e impositivo de acuerdo a los compromisos interpuestos por la normativa jurídica laboral
(Fedesarrollo, 2018). En Colombia, esto implica un aumento en la rigidez del mercado laboral y en los niveles de desempleo.

Por otro lado, se infiere que existe un selecto grupo de naciones con graves problemas de desplazamiento de población derivados de distintas causas, entre las que resaltan la violencia interna, conflictos armados y factores económicos. En ese sentido, existen datos proporcionados por la Organización Internacional para las Migraciones (OIM), según los cuales Colombia se muestra como un gran generador de emigrantes y receptor de inmigrantes al mismo tiempo, veamos entonces las siguientes cifras, según las conclusiones de la OIM (2018, p. 42):

Los 40,3 millones de desplazados por la violencia y los conflictos a finales de 2016 han sido acogidas en 56 países y territorios, [...] Colombia (con 7.246.000 de desplazados) y la República Árabe Siria (6.326.000) superan con creces al resto de países, y juntas representan casi un tercio de la población mundial de desplazados. Les siguen el Sudán (3.300.000), el Iraq (3.035.000), la República Democrática del Congo (2.230.000) y luego el Yemen, Nigeria, Sudán del Sur, Ucrania y el Afganistán. De los 40,3 millones de desplazados, más de 30 millones se encuentran en estos diez países. De hecho, Colombia, la República Democrática del Congo, el Iraq, el Sudán y Sudán del Sur se sitúan entre los diez primeros países de la lista desde el año 2003.

Por su parte, Colombia en el año 2017 albergó una cantidad de 1.622.109 venezolanos, y para el año 2018, el éxodo masivo de venezolanos por razones político-económicas se prolongó. Los venezolanos, buscando ingresar en otros países, cruzan la frontera a causa de la caída del nivel de vida como efecto 
del deterioro económico de la moneda nacional, y por ende del poder adquisitivo desbastado por una brutal hiperinflación, la caída de la producción y el deterioro del salario laboral (Bermúdez, Mazuera, Albornoz y Morfefe, 2018).

Así mismo, los citados autores (2018, p.4) citando a OIM, destacan que ese éxodo comenzó a mediados del año 2012, "...observando un fenómeno de movilidad humana en el cual se distinguen las siguientes caracterizaciones: es un proceso complejo, porque las razones para emigrar emergen entre dos vías: voluntarias o forzadas, y la temporalidad va desde lo pendular, es decir, ir y venir a los países fronterizos (especialmente Colombia) hasta la decisión definitiva de marcharse del país por un largo período".

Además, Bermúdez et al. (2018) afirman que para el año "2015 entraron regularmente a distintos países receptores 697.562 venezolanos"; y en la actualidad, pese a los esfuerzos, se hace difícil determinar con exactitud cuántos de esos migrantes decidieron quedarse en Colombia; incluso se duda de algunas fuentes y cifras por considerarse que los mecanismos empleados para la interpretación de la movilidad migratoria son insuficientes, si se tiene en cuenta la porosidad o permeabilidad característica de la frontera colombiana (Bermúdez et al., 2018).

Hoy día, se sabe que la mayoría de las causas que movilizanalas diferentes poblaciones suramericanas suelen ser de índole económico-laboral producto de efectos inducidos desde la dinámica de la geopolítica internacional; sin embargo, esta afirmación no constituye un elemento esencial desde el punto de vista de la presente investigación, no obstante, se menciona como referente necesario en la contextualización sobre lo que sucede en Colombia como país receptor, poniendo de lado, por supuesto, los intereses o sesgos políticos que circundan este fenómeno social.

Al mismo tiempo, se pueden hacer otras caracterizaciones, porque aún persisten interrogantes acerca de la motivación de los migrantes y refugiados, por ejemplo, si migran en busca de alimentos, tratamientos de salud, trabajo o educación, y determinar, además, su estatus de legalidad o su responsabilidad en cuanto a si son víctimas de la crisis vivida en sus países de origen. Según la Unesco (2019), estas discusiones pueden desviar la atención del bienestar de los migrantes y refugiados, quienes merecen respeto a sus derechos humanos. Entonces, en este caso, se pueden inferir una serie de situaciones posibles:

a) Los migrantes se desplazan más allá de las fronteras para trabajar, ya sea con autorización del país de acogida o no.

b) Si reciben apoyo legal, en relación con la necesidad de poseer documentos requeridos por las leyes y la normativa de inmigración para entrar, residir o trabajar en un país como Colombia.

c) Los mecanismos para solicitar refugio en caso de ser víctimas de persecuciones en otro país y cuya solicitud debe ser tramitada oportunamente por el Estado receptor.

d) Si los solicitantes de asilo tienen éxito en sus trámites, en cuanto a obtener el estatus de refugiados para el alcance y protección de derechos humanos en virtud de tratados internacionales.

Considerando esas situaciones de corte normativo, para un país como Colombia la inmigración puede lógicamente encender las alarmas, porque llega precisamente en un momento histórico en el que no se tiene la mejor perspectiva económica y en medio de un débil tratado de paz que no da garantías para concluir la guerra interna. Entonces, en el marco interno nacional se torna difícil de resolver, porque pueden existir limitaciones para garantizar los derechos, tanto de los migrantes transeúntes que se dirigen a otros países como de aquellos que desean permanecer en el territorio colombiano.

Por dar un ejemplo, la mayoría de las migraciones latinoamericanas ocurren como resultado del agravamiento de la situación de los países, es decir, como efecto de una crisis que causa el despoblamiento de sus regiones, quizás porque no se le garantiza a la población una remuneración digna por su trabajo, como tampoco se responde a la necesidad de acceso a los insumos básicos para la vida como el de la salud y la alimentación. La intervención del Estado no es efectiva para evitar la emigración de sus conciudadanos, y solo 
alcanza a responder en aquellos casos en los que los ciudadanos migrantes manifiestan ante las autoridades consulares que han sido víctimas de violación de sus derechos humanos en los países anfitriones.

Contrariamente a lo que indican las tendencias normativas de los organismos humanitarios como las Naciones Unidas (ONU), la migración en Colombia no es vista como un fenómeno benéfico, lo que contradice la visión de observarla como "una gran fuerza de movilización positiva en la historia y el desarrollo de la humanidad" (Unesco, 2019). Por lo menos Colombia trata de cumplir el principio de dar refugio como parte de sus obligaciones con el derecho internacional, en cuyo caso se establece que los inmigrantes no deben ser devueltos a lugares donde sus vidas o libertades corren riesgos.

Sobre el tema de la inmigración y los motivos de su desplazamiento, tampoco se puede obviar que internamente proyecta en Colombia una serie de desafíos que tienen impresión en los ámbitos territorial y extraterritorial. El primer ámbito obedece a la capacidad de respuesta del Estado para contribuir a la solución de los problemas migratorios que se dan en cada uno de los departamentos y poblaciones ubicados en las zonas fronterizas, y en las rutas por donde pasan las columnas de migrantes, con el fin de cumplir con el propósito normativo que obliga a proteger a estos viajeros considerados como población en riesgo o vulnerable a la violación de sus derechos humanos.

\section{En cuanto a la definición de trabajador cualificado}

Antes de continuar con las explicaciones de este estudio bibliográfico, es prudente detenerse para explicar el término cualificado/a. Según la Real Academia Española de la Lengua (RAE, 2014), es el participio de cualificar, lo cual quiere decir calificado, de autoridad, mérito y respeto; y este término se usa como forma de describir la buena calidad de las labores emprendidas por la persona en cumplimiento de las tareas productivas que realiza para su subsistencia. Esto implica que posee formación especializada para desempeñar una actividad productiva profesional del mismo nivel de conocimiento adquirido a través del estudio formal. Por su parte, para la CEPAL (2011, p. 37) el capital social está asociado al nivel de instrucción y la lengua, el cual se prueba por medio de la homologación de títulos. En contraposición, define también el término trabajadores "no cualificados" como mano de obra con poco nivel de instrucción profesional; en época de crecimiento económico hay demanda de trabajadores no cualificados.

En época de crisis [...] la ventaja era tener un mejor nivel de cualificación, lo que demandaba formación y derecho al acceso a becas; por tanto, en ese tiempo los trabajadores migrantes no calificados sufrían más, pues salir del desempleo era más fácil para los calificados. (CEPAL, 2011, p. 37)

Para Martínez (1989), hablar de la emigración del recurso humano calificado es referirlo como valioso para un país en desarrollo. Sin embargo, también se define como una pérdida social y económica para el país de origen, sin importar el destino del emigrante. Esto plantea, además, que existe desde entonces el interés por la discusión y el estudio de la cualificación del trabajador, como forma de expresión circunscrita meramente al "éxodo intelectual".

\section{Aspectos derivados del estudio de la cualificación como necesidad recurrente en países en vías de desarrollo}

En algún momento, podrá comprenderse que la migración hacia Colombia posee varios efectos positivos sobre la economía colombiana, si se considera el punto de vista de los industriales. Frente a esa creencia, existen dos escenarios bien definidos que contienen sus propios indicadores:

a) Beneficio demográfico: El cual se obtiene mediante el ingreso de una población migrante que en promedio es cinco años más joven que la población local, lo cual implica un aumento en el segmento de población en edad productiva.

b) Beneficio en aumento comercial y consumo: Resulta evidente que este aspecto es un efecto positivo, principalmente para las entidades departamentales fronterizas, porque se observan aumentos sobre el consumo, la 
productividad y el nivel de emprendimiento, los cuales son indicadores esenciales para medir el desarrollo económico que permite impulsar el crecimiento económico en el corto y mediano plazo (Fedesarrollo, 2018).

En ese sentido, se expresa que la migración puede significar una regalía para el país anfitrión, si se la observa desde la perspectiva de la cualificación como elemento indispensable para la mejora de los procesos productivos necesarios para el crecimiento potencial de la economía, siempre y cuando se logren articular las estrategias para el ordenamiento social con el aumento de la población en edad productiva; es decir, se verán efectos positivos cuando se logre vincular formalmente al inmigrante con el mercado laboral, y junto a este logro vendrían otros beneficios para la nación tal como la incidencia en el aumento de las contribuciones a los sistemas de seguridad social y al sistema tributario.

Se han observado pocos avances para alcanzar una política regional idónea para atender el tema migratorio, por lo menos que esté asentada en estrategias de integración y en la cooperación multilateral, asegurando que las estrategias, instrumentos y normatividad empleados por los Estados estén sujetos al interés propio de cada nación, es decir que se aplican a través de conceptos e interpretaciones propios en cuanto al control de sus fronteras (Álvarez, 2012).

En ese sentido, los colombianos han tratado de construir sus propias políticas migratorias de corte contentivo, sin sopesar algunos aspectos positivos que se observan en las poblaciones fronterizas y otras grandes ciudades como Bogotá, Medellín o Barraquilla, por mencionar solo tres que son preferidas por los migrantes, donde se ha identificado la presencia de extranjeros con niveles de competencias y cualificación que incluso superan la media colombiana.

Por su parte, para Bermúdez et al. (2018) las competencias de los inmigrantes son un tema importante para iniciar una reflexión de cara a indagar las características de este fenómeno que se está abordando, y el cual han comenzado a calificar como migración laboral, precisamente porque ante el deterioro del salario, los migrantes buscan, con sus títulos académicos en mano, nuevas oportunidades de empleo que les permitan acceder al nivel de vida que estaban acostumbrados antes de que sucediera la crisis.

Por lo menos esa expresión también es compartida por la Organización Internacional del Trabajo (OIT), para la cual en las migraciones latinoamericanas se concentra un porcentaje importante de personas altamente cualificadas para ejercer en distintas áreas profesionales y técnicas, lo cual nos deja en condiciones de vulnerabilidad y fragilidad ante las dimensiones del problema de la movilidad fronteriza.

Al respecto, son pocos los mecanismos de protección para evitar incluso la explotación laboral, de la cual son objeto muchos migrantes, por ello, la OIT (2013a) viene informando sobre la necesidad de crear un sistema jurídico de amplio espectro (nacional e internacional) donde se permita hacer una separación funcional entre la legislación laboral y las normas de inmigración, con el propósito de que los gobiernos brinden a los migrantes indocumentados la posibilidad de poder trabajar y ser representados de manera anónima por sindicatos ante los tribunales laborales. Se entiende que lo ideal sería que a través del empleo se promueva la inclusión social y la legalización del migrante, lo cual promueve su inclusión social, y citan como ejemplos: Argentina, Brasil, Italia, Panamá, Sudáfrica, España, Tailandia, entre otros.

Para los colombianos la inmigración es comprendida como "ingreso y permanencia de los extranjeros en el país", lo que incluye el hecho de que posean visas, demuestren que adelantan una ocupación, profesión o actividad en el territorio nacional, y que se compruebe la autenticidad de documentos en cuanto a la verificación de parentesco, convivencia marital, entre otros aspectos jurídicos (todo esto como indicadores de esa condición) (Migración Colombia y OIM, 2017).

En ese sentido, la visión colombiana frente a las expectativas internacionales no considera a los indocumentados como migrantes sino, más bien, como intrusos, es decir, tomando en cuenta 
lo limitado de la definición, son calificados de ilegales, por lo tanto, se criminalizan y son objeto de sanciones, aun cuando se trate de profesionales y técnicos. Una conducta que se asemeja a las implantadas en países desarrollados como Estados Unidos y cualquier país de Europa, claro está con sus excepciones.

Entonces desde esa perspectiva, se establece el supuesto de que existen dos conceptos antagónicos, por un lado, el de inmigrante legal y, por el otro, el de inmigrante ilegal, respondiendo a la lógica no explicada de las autoridades de migración de Colombia. Sin embargo, puede suponerse igualmente que la cualificación del inmigrante tampoco resulta importante, como tampoco es relevante demostrar que se es productivo. Por estas razones, la OCDE y la Acnur (2018, citados por Unesco, 2019, p. 177), explican lo siguiente:

Los inmigrantes indocumentados y los solicitantes de asilo no siempre tienen derecho legal a trabajar, lo que les desanima para seguir sus estudios, en especial, la formación profesional promovida por el empleador, puesto que los empleadores son renuentes a contratarlos.

\section{Revisión del concepto de inmigrante como elemento importante que impacta en los indicadores del desempleo de la nación anfitriona}

Según la OIM (2018), las migraciones son movimientos poblacionales masivos, en los que las personas se desplazan de su lugar natural de residencia a otros lugares del mundo que aprecian como una oportunidad para mejorar sus condiciones de vida. Salen de su hogar con el deseo de radicarse en un país de acogida de forma provisional, temporal o permanente.

Por su parte, Micolta (2005, p. 60) las describe como "desplazamientos o cambios de residencia a cierta distancia -que debe ser significativa- y con carácter relativamente permanente o con cierta voluntad de permanencia". De las diversas explicaciones puede entenderse que las migraciones son un proceso de decisión personal, que puede ocurrir por cuenta propia o por circunstancias forzosas que impliquen el riesgo de la propia vida.
En ese sentido, pueden diferenciarse dos términos que describen perspectivas distintas sobre un mismo proceso, ambos necesarios para comprender este fenómeno:

a) inmigración implica la acogida de personas en un país anfitrión, el migrante es quien elige su destino por motivos económicos, políticos, sociales o culturales.

b) La emigración, que marca un sentido diferente, se define como las personas que toman la decisión de abandonar el país de origen en busca de nuevas oportunidades o porque huyen de algún peligro.

En consecuencia, gracias a estas terminologías puede establecerse una relación dinámica de orden jurídico y cooperacionista entre una nación impulsora, la propia persona migrante y el país receptor o anfitrión. También, puede hacerse una relación según la duración del migrante con el país anfitrión, la cual puede darse de la siguiente manera:

a) Migrante permanente: el migrante sale de su país de origen con la decisión de establecerse en el país receptor, se trata de desplazamientos en los que se buscan oportunidades de superación o de protección, y en los que la posibilidad de lograr un trabajo se identifica como única herramienta que le permitirá cumplir con un proceso de asimilación social y normativa necesario para asentarse en el país, demostrando su valor como persona productiva.

b)Migrante temporal: se refiere a los casos de desplazamientos dados ocasionalmente, principalmente por motivos laborales, aunque también se pueden dar por razones de cobijo provisional. Cuando ocurren por razones laborales, se evidencian en ciertas zonas del mundo épocas en las que se requieren trabajadores con determinadas cualidades para cubrir una demanda productiva empresarial. Estos migrantes no pretenden radicarse en el país anfitrión, sino que justifican su movilidad con el propósito de aumentar sus ingresos para regresar a disfrutarlos en su país de origen. 
Esta explicación obliga a suponer que cuando un migrante se moviliza con el propósito de radicarse en el país receptor debe preocuparse por hacerlo de forma legal (si quiere tener éxito), y eso conlleva demostrar su cualidad laboral con títulos de estudio apostillados, porque el concepto migrante permanente trata de describir un conjunto de personas que poseen las condiciones idóneas exigidas por el país de acogida. Esto implica ventajas a la hora de adjudicar permisos de residencia de forma temporal o permanente, mediante los cuales la persona gozaría de todos los derechos y obligaciones que le comprometen por ser residente del país al que decide emigrar.

Por otro lado, un migrante como persona que atraviesa las fronteras de forma irregular, sin presentar los requisitos legales (pasaporte 0 visado) necesarios para poder acceder al país, es un ilegal, o posee esa condición, que solo la pueden explicar los juristas. Ser un inmigrante ilegal supone un riesgo para el migrante en cuanto al respeto de sus derechos humanos. En la mayoría de los casos, el ingreso no autorizado a los países de acogida significa un problema de seguridad personal, con grandes dificultades para los emigrantes, quienes deben enfrentar situaciones de todo tipo, de hecho, se les cataloga como población vulnerable a la cual los Estados deben brindar especial atención.

Existen otras denominaciones que fragmentan el concepto de inmigrante, una de ellas es el término de refugiado: se trata de personas que logran salir a otro país en busca de protección y que no pueden regresar debido a problemas políticos, guerras o persecuciones. Se diferencia del resto de migraciones en que en ésta el migrante no decide ni planifica su viaje (OIM, 2018).

Dentro del ámbito de los desplazamientos migratorios, se pueden contar dos subclasificaciones:

a) Interna: Cuando las movilizaciones poblacionales ocurren dentro del mismo país o región a la que pertenece la persona que decide migrar.

b) Externa: Cuando los sentidos de la movilidad se originan fuera de los países anfitriones, lo cual se denota como desplazamientos migratorios internacionales.
Ahora bien, según el grado de cualificación de las personas movilizadas, las migraciones pueden clasificarse como:

a) Baja formación: Se refiere al conglomerado poblacional que ha tenido dificultades para acceder al derecho a la educación y poder formarse de una manera más competitiva. De forma general, se trata de personas que acceden a puestos de trabajo mal remunerados y poco cualificados por no poseer mayores niveles de formación, sin embargo, también contribuyen al desarrollo del país porque refuerzan la mano de obra necesaria para la producción del campo y de la industria en general, ocupando puestos que por lo general no son deseados por profesionales y técnicos.

b) Alta formación: Describe el tipo de población migrante que demuestra un alto nivel de formación, cuya decisión de movilizarse es producto de la poca posibilidad de percibir una remuneración acorde con sus capacidades y habilidades; donde también se resaltan las limitaciones al acceso a las nuevas tecnologías.

\section{La cualificación del empleo desde la pragmática de los países desarrollados: Referencias para dibujar la inmigración en Colombia.}

Los grandes flujos de migrantes que se producen de forma espontánea en el continente suramericano no son muy frecuentes, con excepción de aquellos que han sido producto de los conflictos armados o desastres naturales. Sin embargo, por lo observado hasta ahora a través de las distintas fuentes, desde las perspectivas de los gobiernos la tendencia es a ver las migraciones como un problema de grandes proporciones, y eso es evidente en el caso de los migrantes latinoamericanos que entran a Colombia, situación que obligó al presidente de este país a solicitar ayuda económica a los países que integran las Naciones Unidas y la Unión Europea y a los Estados Unidos, lo cual le fue concedido (Reuter, 2019; AFP, 2018; Noticias ONU, 2018).

Como diferencia de los vocablos negativistas, se puede resaltar que en relación con las migraciones no todo es malo, porque sí existe un conjunto de efectos benéficos para el país de acogida, claro que estos efectos se observan con mayor claridad a 
largo plazo y dependen de las condiciones generales ofertadas por la nación anfitriona, mientras que los efectos negativos se producen de inmediato (Moreno, 2016).

Se puede estar de acuerdo en que uno de los principales aspectos de la inmigración se concentra en la fuerza laboral del país receptor, lo que afecta directamente la oferta de puestos de empleo y fuerza una caída de los porcentajes de la demanda de las vacantes disponibles, con un posible aumento de la tasa de desempleo de los trabajadores locales. Es decir, si el aumento de la ocupación de puestos laborales por los emigrantes, como parte de la ecuación que causa el descenso de la oferta de la canasta laboral, no se acompaña de un crecimiento de la demanda por parte de los trabajadores locales, puede ocasionar un aumento de los índices de desempleo, como también una contracción o estancamiento de los salarios, o pueden suscitarse los dos casos a la vez. Ante esto, debe advertirse que la solución no es negar empleo a los inmigrantes, porque se estaría creando un problema distinto que golpea el renglón de la seguridad ciudadana, e incluso se pondría en estado de peligro a esa población migrante, la cual buscará cualquier medio para garantizar su subsistencia (OIT, 2018).

Para continuar con esta idea, la inmigración puede considerase como una solución a la diatriba generada dentro del sector productivo nacional, en cuanto al requerimiento de mano de obra especializada, si se considera que para ser competitivos en el mercado mundial se debe invertir constantemente en aumentar la cualificación de los trabajadores de la nación anfitriona; como alternativa, el Estado puede ahorrarse tiempo y dinero si acepta la mano de obra migrante como parte de un modelo de expansión de la economía del país.

Para dar un ejemplo, se pueden observar las políticas de inmigración desarrolladas por los canadienses, que resuelven dos problemas: uno, aumentar su poder productivo; el otro, ayudar a poblar y desarrollar las regiones creando nuevos asentamientos productivos (Moreno, 2016).

Entonces, para equilibrar la entrada de la mano de obra inmigrante, se debe ampliar la capacidad nacional en cuanto a políticas que estimulen la creación de más empresas, lo cual tendrá sin duda resultados positivos en relación con la cantidad y calidad de lo que se produce. Por ejemplo, en épocas de expansión, la entrada de trabajadores cualificados de otros países puede contribuir a la innovación y provocar un descenso del desempleo en el país. En el caso contrario, que se perciba el ingreso de una población no cualificada, puede considerarse como un obstáculo para el crecimiento económico de la nación.

Ahora bien, en tiempos de recesión de la nación anfitriona, la mano de obra cualificada puede desplazar al empleado nativo en muchos puestos de trabajo, porque la fuerza laboral que ingresa al país de destino entra a competir de manera directa en el mercado laboral que requiere mano de obra experta. En este punto, el análisis se centra en que los locales son desplazados porque el sector empleador se aprovecha de bajar costos a expensas de pagar menores salarios al inmigrante; es decir, la mano de obra nativa resulta más costosa y por esa razón es reemplazada.

\section{Análisis teórico: El aporte de la mano de obra cualificada al desarrollo de los países}

La atención se puede concentrar ahora en los aspectos macroeconómicos sustentados por las teorías del desarrollo. Estas proposiciones contribuyen a profundizar en los procesos estructurales e internacionales referentes a la migración internacional, la cual siempre ha existido, incluso históricamente, desde épocas coloniales, ha desempeñado un rol importante dentro del movimiento del mercantilismo, la industrialización y el capitalismo mundial.

Los referentes teóricos clásicos presentan dos enfoques bien conocidos: La teoría del desarrollo económico que apunta a los modelos neoclásicos de cambio estructural, y los modelos de dependencia internacional. El primero centra el análisis en los mecanismos que emplea un país subdesarrollado para transformar su economía tradicional de subsistencia a una estructura económica mucho más moderna. Esto, como base representativa del estudio realizado por Lewis (1954) para explicar los excesos de mano de obra derivados de procesos como las migraciones. 
En ese sentido, se habla sobre la expansión del sector industrial capitalista, que se sustenta en una oferta de trabajo barata procedente del sector tradicional de subsistencia. Este modelo proporciona una de las primeras explicaciones económicas que aún tienen vigencia en nuestros días. En ese sentido, los enunciados básicos de este modelo, serían:

a) Dentro del nivel de subsistencia, la oferta de la mano de obra es ilimitada, siendo su productividad marginal igual a cero, o incluso negativa.

b) El crecimiento económico se debe a la acumulación de capital, es decir al excedente, siendo éste la diferencia entre el salario real de la industria y el salario institucional de subsistencia del sector tradicional, y es reinvertido en la generación de un sector moderno.

Ahora bien, según lo explicado dentro de este modelo, la causa de la emigración es la diferencia de salarios entre el lugar de origen y el de destino. La cuestión más importante es entonces responder la interrogante sobre cuáles sectores ofrecerán mano de obra adicional: si el sector industrial demanda trabajo a salarios más bajos, como respuesta se interpreta de Lewis-, el sector empresarial aprovecha las migraciones porque en ellas se tiende a capturar ese tipo de mano de obra, a pesar de ofertar un salario de subsistencia muy por debajo del recibido por el sector laboral local desplazado.

En todo caso, el sector productivo empresarial sólo contratará a aquéllos cuyo salario sea menor al de la productividad media, que es igual al salario de subsistencia, en un margen que generalmente se establece como del $30 \%$ de los costos de producción. Entonces, se subcontrata a los trabajadores bajo la figura de trabajadores ocasionales o temporeros ocasionales, y los dividen en un sinfín de nuevos segmentos en los que se incluye el método de tercerización del empleo, en el que se incorpora a la población activa (mujeres) y los trabajadores del comercio al por menor.

Bajo la luz de esta teoría, si la oferta de trabajadores con la entrada de los inmigrantes se consideraba ilimitada, es de suponerse que esto provocaría una curva de oferta ascendente de puestos de empleo, porque ofrece la posibilidad de hacer rendir los presupuestos de pago de mano de obra, es decir, por cada salario de un trabajador local podía ahora contratarse a varios inmigrantes posiblemente mejor cualificados. Con la consecuencia que, dentro de un punto de inflexión, podría producirse un mayor grado de escasez de puestos de trabajo para los locales.

Por su parte, Raj y Sen (1962) desarrollan los modelos anteriores introduciendo en este análisis el sector exterior, del cual dicen como máxima teórica que la dependencia de los países subdesarrollados puede dar sentido a las explicaciones de las migraciones, que van unidas a la penetración del capital en la estructura socioeconómica de los países, lo que quiere decir que la mano de obra emigra hacia donde está el capital; para dar un ejemplo, esto explica perfectamente lo que ocurre en la frontera compartida entre México y Estados Unidos.

Sassen (1988) observa con normalidad la propia movilidad del capital y justifica el hecho de creación de nuevas condiciones que permiten la movilidad del trabajo para beneficiar el desarrollo como parte positiva de las migraciones hacia el país anfitrión. En estos términos, el aporte de este autor es importante para nuestro análisis, porque propone una variable, no como causa directa, sino como la esencia de una nueva estructura que permite generar condiciones para que la migración sea una forma de inversión extranjera directa para los países receptores.

Esto tiene lógica si se plantea que dentro del capitalismo la cualificación de trabajadores tiene un valor, una inversión en educación. A esto se suma que detrás de los inmigrantes suelen venir nuevos emprendimientos como oportunidades de negocios para el sector económico de la nación anfitriona.

\section{Consideraciones finales}

Frente a los inmigrantes existen muchas distinciones entre los casos de migrantes cualificados y no cualificados, así como la mezcla de esos términos para unirse a las condiciones de legales e ilegales. 
En definitiva, para la mayoría de los inmigrantes lo importante es llegar a competir por puestos de trabajo, así sean de un nivel bajo de formación (porque ese es su objetivo, trabajar para costear sus gastos de supervivencia), o por otras tantas plazas rechazadas por la mano de obra nativa por considerarlas mal retribuidas, con condiciones laborales extremas en cuanto a la seguridad y el riesgo.

Otros efectos considerados negativos que puede llegar a ocasionar la entrada de migrantes, según la OIT (2016), son:

a) La limitada financiación a los países de acogida, los cuales se ven limitados a prestar servicios a los migrantes.

b) Dificultades para hacer valer los derechos de los inmigrantes, en cuanto a ayudar a su integración en condiciones de derechos humanos de igualdad, seguridad social, salud y educación en condiciones de dignidad.

c) El respeto cultural del migrante, porque suelen existir problemas de discriminación como parte de un choque entre culturas de la población local y la inmigrante.

d) La inmigración ilegal puede producir un aumento del comercio informal, el cual genera pocos ingresos al Estado por concepto de impuestos; sin embargo, contribuye con la estabilización de los precios del mercado local al ofertar productos a precios competitivos.

e) Aparición de tratos discriminatorios, conflictos, xenofobia, intolerancia y racismo por la llegada de trabajadores inmigrantes. Todo esto puede ser probable en el caso de la migración de distintos países hacia Colombia.

Al mismo tiempo, tampoco se puede negar que la llegada de los inmigrantes ha traído efectos positivos, entendiendo que estos inmigrantes han fortalecido aquellas áreas laborales que no quieren ser ocupadas por los propios colombianos, como es el caso de la producción agrícola. También, cuando la mano de obra es cualificada contribuyen al mejoramiento de los procesos productivos, pues traen consigo técnicas y saberes que no se conocen en el país, lo cual contribuye sin duda al crecimiento económico con un amplio espectro, que permitirá que los productos colombianos sean más competitivos en el mercado internacional. En ese sentido, se destacan los siguientes efectos:

a) Contribuyen a evitar el estrangulamiento del mercado de bienes y servicios.

b) reduce un rejuvenecimiento de la población.

Además, se observó que la inmigración de la mano de obra cualificada en el caso de Colombia, puede resultar para este país una solución para evitar un aumento de las tasas de dependencia al traer nuevos conocimientos a los sectores productivo y educativo locales, lo cual a largo plazo redundará como elemento que contribuye al desarrollo de la nación como potencia regional latinoamericana. Para esto, se considera mejorar las políticas de asimilación de los migrantes en su generalidad más amplia.

Desde el punto de vista neoliberal, la migración cualificada comporta un incremento del capital humano, sin que repercuta en un costo para Colombia, aparte de que regula los costos del mercado laboral al estabilizar los sueldos y salarios; a lo que se añade que reduce la posibilidad de incrementos de bienes y servicios, producto precisamente de mantener estables las nóminas empresariales. Es decir, el principal beneficio ha sido provocar una reducción de los costos para las empresas, y que al mismo tiempo se mejoran los procesos para optimizar la capacidad competitiva del país anfitrión. 


\section{Referencias bibliográficas}

AFP Agencia (12 de abril de 2019). "Banmundial entrega USD 31,5 millones a Colombia para atender a migrantes venezolanos". El Heraldo. Recuperado de https://www.elheraldo.co/colombia/ banmundial-entrega-usd-315-millones-colombiapara-atender-migrantes-venezolanos-619392 [Consultado el 09/08/2019]

Álvarez, I. (Comp.) (2012). Mirando al Norte: Algunas Tendencias de la Migración Latinoamericana. Costa Rica: Ford Foundation Institute.

Bermúdez, Y., Mazuera, R., Albornoz, N. y Morffe, M. (2018). Informe sobre la movilidad humana venezolana. Realidades y perspectivas de quienes emigran [9 de abril al 6 de mayo de 2018]. San Cristóbal, Venezuela: Fundación Entreculturas Servicio Jesuita a Refugiados (SJR).

Fedesarrollo (2018). Informe Mensual del Mercado Laboral: Migración venezolana a Colombia. Bogotá: Gráficas Ducal Ltda. Recuperado de https:// www.fedesarrollo.org.co/sites/default/files/imloctubre_2018-web.pdf [Consulta 10/08/2019]

Freitez, A. (julio, 2011). La emigración desde Venezuela durante la última década. Revista Temas de Coyuntura, (63), 11-38.

Lewis, W. (1954). Desarrollo económico con oferta ilimitada de mano de obra. El trimestre económico, (108), 629-673.

Martínez, J. (1989). La migración de mano de obra calificada dentro de América Latina. Santiago de Chile: Centro Latinoamericano de Demografía (Celade).

Micolta, A. (2005). Teorías y conceptos asociados al estudio de las migraciones internacionales. Trabajo Social, (7), 59-76. Colombia

Migración Colombia y OIM (2017). Oportunidades de la migración internacional en un contexto de paz en Colombia. Ejercicio institucional prospectivo de las dinámicas migratorias en el posacuerdo. Bogotá: Procesos Digitales SAS.

Moreno, F. (2016). Inmigración (XXXV): los no cualificados también son necesarios. Recuperado de https://www.juandemariana.org/ijm-actualidad/ analisis-diario/inmigracion-xxxv-los-nocualificados-tambien-son-necesarios [Consulta 10/08/2019]
Noticias ONU (2018). "La ONU incluye por primera vez a Venezuela en el plan anual de ayuda humanitaria". Disponible en: https://news.un.org/ es/story/2018/12/1447051 [Consultado el 09/08/2019]

Organización de las Naciones Unidas (ONU) (2011). "Aspectos emergentes y novedosos de la migración latinoamericana a España". En Taller sobre el fortalecimiento de las capacidades nacionales para la gestión de la migración internacional: nuevas tendencias, nuevos asuntos, nuevos enfoques de cara al futuro (pp. 34-38). Santiago de Chile: CEPAL.

Oficina Internacional del Trabajo (OIT) (2013). Migración laboral y desarrollo: la OIT sigue avanzando. Tripartita sobre las Migraciones Laborales. Ginebra: OIT, Servicio de Migraciones Laborales.

Oficina Internacional del Trabajo OIT (2016). Migraciones Laborales. Fuentes de información de la OIT. 2. a ed. Serie: Bibliografías Temáticas Digitales OIT, N.ำ 7. Oficina Regional para América Latina y el Caribe Lima: OIT, Ginebra.

Organización Internacional para las Migraciones (OIM) (2018). Informe sobre las migraciones en el mundo 2018. Ginebra: OIM.

RAE (2014). Diccionario de la Real Academia Española de la Lengua. Recuperado de https://dle.rae. es/?id=BRRLNRf [Consultado el 09/08/2019]

Raj, K. y Sen, A. (1962). Alternatives Patterns of Growth: A reply. Oxford Economic Papers.

Reuters (8 de agosto de 2018). Nueva donación de EE. UU. a Colombia para la atención de venezolanos. El Tiempo.com. Recuperado de https://www.eltiempo. com/colombia/otras-ciudades/dinero-que-recibecolombia-para-ayudar-a-los-venezolanos-253584 [Consultado el 09/08/2019]

Sassen, S. (1993). La movilidad del trabajo y del capital. Un estudio sobre la corriente internacional de la inversión y del trabajo. Madrid: Centro de publicaciones del Ministerio de Trabajo y Seguridad Social.

Unesco (2019). Migración, desplazamiento y educación: construyendo puentes, no muros. Informe de seguimiento de la educación en el mundo, 2019. París: Unesco. Recuperado de https://unesdoc. unesco.org/ark:/48223/pf0000367436 